University of Nebraska - Lincoln

DigitalCommons@University of Nebraska - Lincoln

Educational Psychology Papers and

Publications

Educational Psychology, Department of

2009

\title{
Teacher-child relationship quality: The roles of child temperament and teacher-child interactions
}

Kathleen Moritz Rudasill

University of Nebraska-Lincoln, kmrudasill@vcu.edu

Sara E. Rimm-Kaufman

University of Virginia, ser4x@virginia.edu

Follow this and additional works at: https://digitalcommons.unl.edu/edpsychpapers

Part of the Educational Psychology Commons

Rudasill, Kathleen Moritz and Rimm-Kaufman, Sara E., "Teacher-child relationship quality: The roles of child temperament and teacher-child interactions" (2009). Educational Psychology Papers and Publications. 126.

https://digitalcommons.unl.edu/edpsychpapers/126

This Article is brought to you for free and open access by the Educational Psychology, Department of at DigitalCommons@University of Nebraska - Lincoln. It has been accepted for inclusion in Educational Psychology Papers and Publications by an authorized administrator of DigitalCommons@University of Nebraska - Lincoln. 
Published in Early Childhood Research Quarterly 24:2 (2009), pp. 107-120; doi:10.1016/j.ecresq.2008.12.003

Copyright (C) 2008 Elsevier Inc. Used by permission.

\title{
Teacher-child relationship quality: The roles of child temperament and teacher-child interactions
}

\author{
Kathleen Moritz Rudasill, University of Louisville \\ Sara E. Rimm-Kaufman, University of Virginia \\ Corresponding author - K. M. Rudasill
}

\begin{abstract}
Young children's relationships with teachers predict social and academic success. This study examines contributions of child temperament (shyness, effortful control) and gender to teacher-child relationship quality both directly and indirectly through the frequency of teacher-child interactions in the classroom. Using an NICHD SECCYD sample of 819 first grade children, four findings emerged: (a) children's shyness, effortful control, and gender contributed directly to teacher-child conflict and closeness; (b) children's shyness contributed to the frequency of child-initiated teacher-child interactions, and children's effortful control contributed to the frequency of teacher-initiated teacher-child interactions; (c) shyness related to teacher-child closeness indirectly through the frequency of child-initiated teacher-child interactions; (d) the frequency of child- and teacher-initiated interactions contributed to each other. Results inform practitioners and researchers of characteristics that put children at risk for failure to form positive relationships with teachers.
\end{abstract}

Keywords: teacher-child relationships, temperament, shyness, effortful control, teacher-child interactions

Relationships are key resources for young children. There is agreement among researchers that the quality of young children's relationships with teachers predicts social and academic performance in school (Hamre \& Pianta, 2001; Lerner, Lerner, \& Zabski, 1985; Pianta, 1999). Positive teacher-child relationships allow children to develop and use effective social skills to negotiate and navigate challenges. Such relationships also provide children with school support systems that act as safety nets in academic and social situations, and promote children's more positive perceptions of school in general (La Paro, Pianta, \& Stuhlman, 2004; Pianta, 1999; Rubin, Bukowski, \& Parker, 1998). Without these social resources, children are more likely to avoid school, report loneliness, and display low levels of academic and social competence (Birch \& Ladd, 1997; Pianta, Nimetz, \& Bennett, 1997).

Because teacher-child relationships are important for children's development, it is necessary to understand the mechanisms underlying their successful formation. Understanding the predictors of high quality teacher-child relationships can inform teacher preparation and professional development, improving teachers' awareness of characteristics that children bring to school that may impact their success. Equipped with a deeper understanding of the correlates of teacher-child relationship quality, teachers may be better able to promote and foster high-quality relationships with more children.

The development of positive teacher-child relationships is multi-determined. Child characteristics, teacher characteristics, and attributes of the social environment all contribute to the nature of children's relationships with teachers (Eisenhower, Baker, \& Blacher, 2007; Kesner, 2000; Mantzicopoulos, 2005; Rudasill, Rimm-Kaufman, Justice, \& Pence, 
2006; Saft \& Pianta, 2001). This work takes a variable-centered approach to examine the contributions of three child characteristics (shyness, effortful control, and gender) to teachers' perceptions of the quality of their relationships with children, as well as the contributions of child characteristics to the frequency of teacher-child interactions, and the contributions of those interactions to teacher-child relationship quality.

\section{Theoretical framework}

Two theoretical models guide this study: the Transactional Model of Development (Sameroff \& Fiese, 2000; Sameroff \& MacKenzie, 2003), and the Ecological and Dynamic Model of Transition (Rimm-Kaufman \& Pianta, 2000). The Transactional Model places emphasis on the bi-directional nature of interactions between person and environment. At the core of this model is the idea that neither the individual nor the environment alone accounts for individual outcomes. Rather, it is the interplay between individual and environment - the transactions between them - that dictates outcomes, with attributes of each influencing the other (Sameroff \& Fiese, 2000). That is, the developing individual is a result of interactions between the individual's genetic make-up and features of the environment (Sameroff, 1983). The ways in which environment influences development are dependent upon an individual's genetic make-up. Conversely, the ways in which genetics inform development are, in part, a product of the environment (Sameroff \& Fiese, 2000). Thus, development is best understood when considering transactions between child and context, and how these contribute to important child outcomes, such as teacher-child relationship quality (Sameroff \& MacKenzie, 2003).

The Ecological and Dynamic Model of Transition (Rimm-Kaufman \& Pianta, 2000) situates elements of the Transactional Model at the period of transition to school, roughly corresponding to ages 4-7. This model posits that children's successful transitions to school are multi-determined, and emerge from combinations of child and contextual characteristics. In addition, this model asserts that the interactions between child and context are bi-directional and always changing, having implications for relationships that impact development. Specifically, teachers influence children and children influence reactions from teachers. These relationships become more patterned over time as participants create expectations and behave in accordance with those expectations, reifying their beliefs about each other in actual behaviors and interactions (Rimm-Kaufman \& Pianta, 2000). From that framework, it is clear that relationships themselves are important outcomes for investigation when studying children in the earliest years of school.

The present study, then, is informed by these two, related models. First, we examine the extent to which child characteristics are linked to teachers' perceptions of the quality of their relationships with children. Second, we examine how child characteristics relate to the frequency of teacher-child interactions, and how child-initiated interactions relate to teacher-initiated interactions, providing information about how child characteristics may contribute to a child's interactions in the classroom. Third, we examine how teacher-child interactions relate to teacher-child relationship quality. Together, these pieces will add to our understanding of how child characteristics may inform both child and teacher behavior (i.e., teacher-child interactions), and how these may contribute to teachers' perceptions of the quality of their relationships with children.

\section{Teacher-child relationships and children's outcomes}

Positive teacher-child relationships appear to operate as protective factors for children's social and academic development (Baker, 2006; Birch \& Ladd, 1997; Pianta, Steinberg, \& Rollins, 1995; Pianta et al., 1997; Valiente, Lemery-Chalfant, Swanson, \& Reiser, 2008). Such relationships are those perceived by teachers to be low in conflict and dependency and high in closeness (Pianta, 1999). In addition, they are marked by respect and caring, with children seeing their teachers as sources of security (Pianta, 1999). Consequently, these types of relationships provide a foundation and model for behavior upon which children can build competence. Birch and Ladd (1997) examined relationships between kindergarteners and their teachers and reported that those students with closer and less dependent relationships also had higher visual and language scores on standardized tests. In addition, higher levels of teacher-child closeness predicted good work habits and fewer internalizing and externalizing problems in later school years (Baker, 2006; Birch \& Ladd, 1997; Hamre \& Pianta, 2001). In a recent study using data from the National Institute of Child Health and Human Development Study of Early Child Care, O'Connor and McCartney (2007) found high quality teacher-child relationships from pre-kindergarten through third grade promoted children's academic achievement in third grade.

Negative teacher-child relationships, on the other hand, characterized by high conflict and dependency, and low closeness, appear to operate as risk factors for children's school success (Pianta, 1999). In negative relationships there is friction between children and teachers, with teachers perceiving children as excessively combative or clingy. Young children in negative teacher-child relationships are more likely to be referred for special services or retained than children in positive relationships (Pianta et al., 1995) suggesting negative relationships fail to provide a secure footing for children, which is especially detrimental during the early years of school (Pianta et al., 1995).

\subsection{Predictors of teacher-child relationships}

What are the predictors of teacher-child relationship quality? Characteristics of the child (e.g., temperament, gender) and teachers' perceptions of children with these characteristics may determine the quality of this relationship. There is evidence suggesting that teacher-child relationships are shaped in part by teachers' perceptions of students' 
dispositional characteristics and behaviors (Buss, Gingles, \& Price, 1993; Evans, 1992, 1996; Saft \& Pianta, 2001; Stuhlman \& Pianta, 2002). Teachers may perceive greater academic abilities in students who readily respond to the rigors of formal schooling (Buss et al., 1993; Keogh, 2003; Lerner et al., 1985); therefore, particular child characteristics (e.g., sitting still and contributing to class activities) smooth children's school transition. Thus, teachers' perceptions of these characteristics are likely to influence their perceptions of the quality of their relationships with children (Keogh, 2003; Saft \& Pianta, 2001; Stuhlman \& Pianta, 2002).

Some child characteristics have been identified as predictors of teacher-child relationship quality (Eisenhower et al., 2007; Hamre \& Pianta, 2001; Ladd, Birch, \& Buhs, 1999). Children displaying antisocial behaviors, such as aggression and withdrawal, often have negative relationships with teachers. Children's antisocial behavior in school has been related to teacher-child relationships high in conflict and low in closeness (Ladd et al., 1999). In a recent study, Eisenhower et al. examined teacher-child relationship quality, and found child behavior problems at ages three and six years are predictive of negative teacher-child relationships at age six. In addition, children displaying aggressive and withdrawn behaviors are likely to have lower levels of teacher-child closeness, higher levels of teacher-child dependency, and higher levels of teacher-child conflict than other children (Ladd \& Burgess, 1999).

Children observed to be self-reliant and have positive affect are described by teachers more positively than are those observed to be less compliant and to display poor classroom behavior (Saft \& Pianta, 2001). In a recent study, teacher-child relationship quality was predicted by the interaction between children's shyness and language ability (Rudasill et al., 2006). Specifically, shyer children with greater language ability tended to be perceived as dependent by teachers, whereas less shy children with lower language ability tended to be perceived as conflictual. In other research, boys are more likely to be perceived as having teacher-child conflict and girls are more likely to be perceived as having teacher-child closeness (Hamre \& Pianta, 2001; Silver, Measelle, Armstrong, \& Essex, 2005). Together, this research indicates that teacher perceptions combine with child attributes to predict teacher-child relationship quality; however, the contributions of child temperament to teacher-child relationship quality have remained largely unexplored, and rarely in conjunction with gender. Thus, one way the present study extends current research is that it explores the contributions of child temperament to teacher-child relationship quality, while considering gender, a frequently identified predictor of teacher-child relationship quality.

\section{Child attributes}

\subsection{Temperament}

Temperament is an individual's general style of responding to stimuli in the environment. It is a biologically based, multi-dimensional construct that begins to emerge during infancy and childhood, is molded by environmental forces, and provides the foundation for personality traits in older children, youth, and adults (Kagan \& Fox, 2006; Rothbart \& Bates, 2006; Thomas \& Chess, 1977). Temperament has been found to be somewhat stable through early elementary school (Kagan, Resnick, Snidman, Gibbons, \& Johnson, 1988; Resnick et al., 1986; Rimm-Kaufman \& Kagan, 2005) and predictive of adult personality traits (Caspi \& Silva, 1995).

Temperament can be conceptualized as a two-system construct; one system is a biologically based reaction to stimuli in the environment (reactivity), and the other system is the regulatory function that operates upon reactivity (regulation). These systems are synergistic, such that a child's behavioral response to events or people is a result of the interaction between these two systems (Rothbart \& Bates, 2006; Strelau, 1983). When considering children's relationships, the reactive system is the tendency to approach or withdraw from the unfamiliar (i.e., shyness), and the regulatory system is engaged to cope with this natural tendency (i.e., effortful control). The dimensions of shyness and effortful control are the focus of the present study.

Shyness describes an individual's style of responding to people, items, or events in the environment that are new or unfamiliar (Asendorpf \& Meier, 1993; Kagan, 1994; Rothbart \& Bates, 2006). Shyer children are those who are apprehensive toward new people, events, and things. They display more cautious behaviors than children who are less shy (i.e., bolder) who approach novelty with ease (Caspi \& Silva, 1995; Kagan, Snidman, \& Arcus, 1992; Rothbart, Posner, \& Kieras, 2006). There is evidence that young children's shyness stems from reactivity in infancy. Highly reactive infants show greater motor and vocal reactions to stimuli, and these behaviors are precursors for shyness when children are 14 and 21 months (Kagan et al., 1992). At age 4, children who had been classified as low-reactive infants talk, smile, and engage in unsolicited speech, whereas those classified as high-reactive infants are more likely to display onlooker behavior, quietly observing (Kagan, Snidman, \& Arcus, 1998). Indeed, infant low- reactive temperament classification is the best predictor of frequent talking to an unfamiliar person at age 41/2 (Rothbart \& Bates, 1998).

Therefore, children classified as shy are likely to have been highly reactive as infants and exhibit fear reactions toward novel or unfamiliar stimuli (Kagan, 1994; Rothbart, Ahadi, Hershey, \& Fisher, 2001). Children classified as not shy are likely to have been low-reactive as infants, and approach-oriented in unfamiliar situations. Thus, high reactivity in infancy and fear in subsequent years seem to contribute to children's shy behavior in school (Rimm-Kaufman \& Kagan, 2005).

High levels of shyness may pose risks to children's relationships, whereas low levels may aid in the successful formation of relationships. Although high levels of shyness are related to children's lower levels of aggression and more empathy (Rothbart, Ahadi, \& Hershey, 1994), suggesting shyness may facilitate positive relationships, children's shyness has also been associated with internalizing behaviors (Olson, Sameroff, Kerr, Lopez, \& Wellman, 2005; Roth- 
bart \& Bates, 1998; Rothbart, Ahadi, et al., 1994; Rothbart, Derryberry, \& Posner, 1994). In fact, Ladd and Burgess (1999) found that social withdrawal (indicative of high levels of shyness) is a risk factor for children's social maladjustment in school. Rydell, Bohlin, and Thorell (2005) found that shyer children are more likely to develop relationships with teachers low in closeness and conflict than their less shy counterparts; this could result from fewer interactions between teachers and children. Indeed, the extant literature indicates that less shy children display higher levels of spontaneous speech and sociability than their shyer peers (Asendorpf \& Meier, 1993; Caspi \& Silva, 1995; Rydell et al., 2005) and such behavior is likely to result in more interactions between teachers and children, particularly childinitiated interactions. There is limited research linking children's characteristics to the frequency and nature of interactions with teachers; however, one study with preschool-aged children revealed shyer children initiate fewer interactions with teachers, and receive more interactions from teachers than their less shy peers (Coplan \& Prakash, 2003). This evidence suggests that lower levels of shyness may facilitate children's abilities to form positive teacher-child relationships. At the same time, although children who are not shy are more likely to interact with others, these interactions are not always positive and may put such children at risk for conflict in their relationships. Thus, children who are not shy may be simultaneously more likely to develop both conflict and closeness with teachers.

The internal regulatory system at work in children's social behavior is effortful control, defined as "the ability to inhibit a dominant response to perform a subdominant response" (p. 137, Rothbart \& Bates, 1998). As such, effortful control is theorized to be a dominant system of temperament (Henderson \& Fox, 1998) that operates upon other more basic temperamental traits, such as shyness. Two dimensions of temperament, inhibitory control and attentional focusing, have been found to work together to contribute to effortful control (Posner \& Rothbart, 2000; Rothbart \& Bates, 1998). Both the ability to inhibit an inappropriate response (inhibitory control) and the ability to attend to stimuli (attentional focusing), contribute to effortful control. For example, a child who is angry with a peer and wants to hit, but instead moves to a quiet activity to "cool down," is engaging both inhibitory control (resisting the urge to hit) and attentional focusing (attending to an alternate activity).

Low effortful control has been associated with children's externalizing behaviors, and, thus, children's problems forming positive relationships in school (Fantuzzo, McWayne, Perry, \& Childs, 2004; Olson et al., 2005; Rothbart \& Bates, 1998; Rothbart, Ahadi, et al., 1994; Rothbart, Derryberry, et al., 1994; Zhou et al., 2007). For example, low levels of effortful control in young children relate to externalizing problems (Rothbart \& Bates, 1998), whereas high levels of effortful control relate to children's social competence and positive peer relationships (Goldsmith, Aksan, Essex, Smider, \& Vandell, 2001). A recent study conducted by Zhou et al. revealed that children displaying consistently high levels of effortful control from ages 5 to 10 are also likely to display low externalizing behaviors in the classroom, as reported by teachers. Put another way, children with high effortful control are less likely to disrupt class and require behavioral intervention by the teacher. Effortful control, then, appears to contribute to children's abilities to successfully interact with teachers and, consequently, form positive relationships with them (Blair, Denham, Kochanoff, \& Whipple, 2004).

\subsection{Teacher- and child-initiated interactions}

To date, research on the contributions of children's temperament to the quality of their relationships with teachers has not included examinations of the contributing role of the frequency of teacher-child interactions. As previously mentioned, there is evidence that shyness and effortful control contribute to the frequency of teacher-child interactions (Blair et al., 2004; Coplan \& Prakash, 2003; Finn, Pannozzo, \& Voelkl, 1995; Keogh, 2003). In addition, the Ecological and Dynamic Model of Transition (Rimm-Kaufman \& Pianta, 2000) suggests that there may be a transactional process between teacher- and child-initiated interactions. That is, children's characteristics contribute to the frequency of teacher- and child-initiated interactions, and these interactions, in turn, contribute to each other. Put another way, children who initiate teacher-child interactions may also be likely to receive more interactions from the teacher. In the same way, teachers who initiate interactions with children may also be likely to put children at ease and, therefore, receive more interactions from children. Conversely, it could be that children who receive more interactions from teachers initiate fewer interactions because they do not want for additional teacher attention. By the same token, it is also possible that children who initiate frequent interactions with teachers actually receive fewer teacher-initiated interactions because teachers perceive them as less needy of teacher attention or more likely to seek help when required. In sum, it is quite reasonable that teacher- and child-initiated interactions may contribute to each other differently. Thus, this study includes an exploration of the contributing role of teacher- and child-initiated teacher-child interactions to each other and to the relation between children's characteristics and the quality of their teacher-child relationships.

\subsection{Gender}

The extant literature suggests that children's classroom behavior and outcomes, as well as teachers' perceptions of children, differ by gender. Researchers have found gender differences in children's inhibited behavior. Specifically, a study of 2-31/2-year-old children showed that boys are shyer than girls in an unfamiliar context, whereas girls are shyer than boys with an unfamiliar person (Kochanska, 1991). Similarly, shy boys and girls behave differently in class, with shy girls and bold boys talking more than their peers (Rimm-Kaufman \& Kagan, 2005). In relation to behavior problems, preschool-aged boys show more internalizing, externalizing, and total problem behaviors than girls (DeSchipper, Tavecchio, Van Ijzendoorn, \& Van Zeijl, 2004; Fantuzzo et al., 2004). In terms of outcomes, children's nonsocial behavior is more deleterious to boys' adjustment to kindergarten than girls' (Coplan, Prakash, O'Neil, \& Armer, 
2004; Nelson, Rubin, \& Fox, 2005). Gender differences have also been detected in teachers' perceptions of children. Boys are more likely to be perceived as having conflictual relationships with their teachers (Hamre \& Pianta, 2001; Saft \& Pianta, 2001), and teachers are more likely to indicate problems with boys' compliance to teacher demands (Stuhlman \& Pianta, 2002). Girls, on the other hand, are more likely to be perceived as having close relationships with teachers (Silver et al., 2005). Taken together, this evidence points to the importance of considering the role of gender when examining the link between children's temperament, the frequency of interactions between teachers and children, and teachers' perceptions of the quality of their relationships with children.

\section{Research questions}

This study combined research in the areas of child temperament (shyness and effortful control) and gender, and teacher-child interactions in order to extend our understanding of the predictors of children's relationships with teachers. Our research questions and hypotheses follow.

1. To what extent do children's temperament (shyness, effortful control, measured at 54 months) and gender directly contribute to teacher-child relationship quality in 1st grade? We hypothesized that children's shyness, effortful control, and gender will directly contribute to the quality of teacher-child relationships such that children with low levels of shyness, low levels of effortful control, and boys will be more likely to have teacher-child relationships high in conflict. Children with low levels of shyness, high levels of effortful control, and girls will be more likely to have teacher-child relationships high in closeness. We hypothesized shyness will contribute to lower levels of teacherchild closeness and conflict based on literature indicating shyer children are less sociable than their less shy peers (Asendorpf \& Meier, 1993; Caspi \& Silva, 1995; Rydell et al., 2005). Conversely, stemming from research pointing to low effortful control as a hindrance to relationship formation (Fantuzzo et al., 2004; Olson et al., 2005; Rothbart \& Bates, 1998; Rothbart, Ahadi, et al., 1994; Rothbart, Derryberry, et al., 1994; Zhou et al., 2007), we hypothesized low effortful control will lead to more teacher-child conflict, and high effortful control will facilitate more closeness.

2. To what extent are child characteristics indirectly related to teacher-child relationship quality through the frequency of teacher-child interactions? We hypothesized that children who are less shy will initiate more interactions with teachers, and children who have lower levels of effortful control will receive more interactions from teachers. Thus, we expected that more teacher-initiated interactions (more likely with children low in effortful control) will predict more teacher-child conflict, and more child-initiated interactions (more likely with children low in shyness) will predict more closeness.

3. To what extent do teacher- and child-initiated teacher-child interactions contribute to each other (i.e., bidirectional) when considering child shyness, effortful control, and gender as predictor variables? We expected to find that more interactions initiated by children will be reciprocated with more interactions initiated by teachers, and vice versa. However, this examination of bi-directionality between teacher- and child-initiated interactions is exploratory.

\section{Method}

\subsection{Participants}

Participants were children and their first grade teachers from the National Institute of Child Health and Human Development Study of Early Child Care and Youth Development (NICHD SECCYD). In 1991, new mothers were recruited for participation in this study from hospitals in regions near the following cities: Little Rock, AK; Irvine, CA; Lawrence, KS; Boston, MA; Philadelphia, PA; Pittsburgh, PA; Charlottesville, VA; Morganton, NC; Seattle, WA; and Madison, WI. Of the 8,986 mothers delivering in these hospitals, 5,416 were eligible for the study and subsequently agreed to a post-hospital follow-up contact by researchers. Of that group, 1,364 mothers and their children were randomly selected to be included in the study; these participants reflected demographic characteristics of the areas from which they were recruited, according to census data. Thus, the sample of 1364 mothers and their infants comprised the NICHD SECCYD. For the purposes of the present study, we accessed data from phase II of the NICHD SECCYD ( $N=1226$ at the start of phase II, due to attrition), which was conducted when study children were between 54 months and the second year of school (typically first grade). First grade teachers became involved in the study if they had study children in their classes. For the NICHD SECCYD, there was typically one child per classroom. However, in 57 cases there were two children in a classroom, and in 8 cases there were three or more children in a classroom. There were too few children per classroom to warrant a nested structure, so in cases where more than one study child was in a classroom, one child was randomly selected for inclusion. In addition, children for whom data on teacherchild relationship quality in first grade were not available $(n=407)$ were eliminated from analysis. The final sample comprised 819 children. We conducted one-way analysis of variance to determine the extent to which children in the final sample $(n=819)$ differed from the children from the original NICHD SECCYD sample $(\mathrm{N}=1364)$ who were not included $(n=545)$ in terms of gender, race/ethnicity, and mother's level of education. There were statistically significant differences for race/ethnicity $(a=.023)$ and mother's level of education $(a<.001)$. For race/ethnicity, $84 \%$ of children in final sample were white, whereas $75 \%$ of not included children were white. For mother's level of education, the average number of years of education for mothers of children in the final sample was 14.48, and the average number of years of education for mothers of children not included was 13.87. 
Child participants included 413 girls and 406 boys. In terms of racial/ethnic composition, $84 \%$ of the sample was Caucasian $(n=692), 10 \%$ was Black or African American $(n=82)$, and the remaining $6 \%(n=47)$ comprised American Indian, Eskimo, or Aleut, Asian or Pacific Islander, or Other. Total annual family income when children were in first grade ranged from $\$ 2500$ ( $1 \%$ of the sample) to $\$ 300,001$ (1\% of the sample). Mean income was $\$ 66,450$, with a standard deviation of $\$ 50,907$. Mothers of participants had a mean of 14.5 years of education $(S D=2.4)$. Teachers of child participants were primarily female $(96 \%)$, and Caucasian $(94 \%)$, with a mean of 14.2 years of teaching experience $(S D=9.4)$.

\subsection{Procedures}

Data for use in this study were collected at two time points: 54 months and 1st grade. The 54-month data were collected from mothers in a laboratory setting. The first grade data were collected through observations of classrooms and from teachers in the spring of the first grade school year. We chose grade 1 data for our study because the NICHD SECCYD included detailed observations of first grade classrooms and this was most proximal to the collection of temperament data at approximately 54 months. Further information regarding sample and selection, data collection, measures, and procedures can be found in the Manuals of Operation of the National Institutes of Child and Human Development Early Child Care Research Network (NICHD ECCRN, 1993).

\subsection{Measures}

\subsubsection{Children's temperament}

Children's temperament was measured when children were $4 \frac{1}{2} 2$ years old using the Children's Behavior Questionnaire (CBQ; Rothbart, Ahadi, et al., 1994; Rothbart, Derryberry, et al., 1994). The CBQ, a parent-report measure for children from 3 to 8 years of age, asked parents to rate their children's behaviors, during the past 6 months, using a 7-point Likert-style rating scale $(1=$ extremely untrue and $7=$ extremely true). The NICHD SECCYD used an abbreviated version of the CBQ containing 8 subscales. We chose three subscales (i.e., shyness, inhibitory control, and attentional focusing) to measure the constructs of shyness and effortful control.

Scores from the 10-item shyness subscale comprised the shyness variable. A higher score on this subscale was indicative of a higher level of shyness (i.e., a shyer child). Shyness subscale items, such as "Sometimes seems nervous when talking to adults s/he has just met" and "Acts shy around new people," measured social inhibition in children. The Cronbach's alpha for this subscale with the current sample was .87.

Effortful control was measured with the 10-item inhibitory control and 10-item attentional focusing subscales of the CBQ. Together, these subscales have been used to assess effortful control (see Olson et al., 2005). Consequently, scores from these subscales were averaged to create effortful control scores. Inhibitory control subscale items, such as "Can easily stop an activity when s/he is told 'no"' and "Has difficulty waiting in line for something (reversed)," measured a child's ability to respond readily to parent or teacher directions. Attentional focusing items, such as "Has a hard time concentrating on an activity when there are distracting noises (reversed)" and "When building or putting something together, becomes very involved in what s/he is doing, and works for long periods," measured a child's ability to concentrate and focus on an activity. Cronbach's alphas with the current sample were as follows: inhibitory control ( $a=.74)$, attentional focusing $(a=.74)$, and the composite of inhibitory control and attentional focusing, effortful control ( $a=.84)$.

\subsubsection{Teacher-child interactions}

The NICHD SECCYD data collection included observations of first grade classrooms. Observational data included frequencies of teacher and child behaviors in areas such as disciplines the study child (teacher behavior) and volunteers to help the teacher (child behavior). For the purposes of our study, teacher-child interactions were derived from classroom observations of time-sampled, behavioral frequencies. Six 10-minute cycles of observations of behavioral frequencies were conducted; each minute comprised $30 \mathrm{~s}$ of observation, followed by $30 \mathrm{~s}$ of recording. During each 30-s segment of an observation cycle, observers noted the presence of a teacher or child behavior, such as interacts with the study child (teacher behavior) or requests help from teacher (child behavior). Observers were trained using videotapes and a manual, and had to achieve $60 \%$ reliability with a master coder prior to conducting observations. According to NICHD ECCRN (2002), "Average exact agreement with the gold-standard videotape test for the timesampled codes was 70\%" (p. 375).

The number of teacher-initiated interactions with the study child was calculated by adding the number of times during the observation cycles that the teacher was observed to interact one-on-one with the study child for at least $5 \mathrm{~s}$. This value was used to assess teacher-initiated interactions in the present study because it a) was coded as teacher behavior toward the study child, b) was restricted to one-on-one interactions between teacher and child, thus verifying that the child was receiving an interaction directly from the teacher, and b) there was sufficient variability in this value across the sample. The types of interactions classified this way included questions directed to the study child, listening to the study child read aloud, and conversations about school work, discipline, and classroom rules. The number of child-initiated interactions, calculated from certain behaviors coded as child behavior toward teacher, was determined by adding the number of times during the observation cycles that the child was observed to request help from the teacher, volunteer to do something upon the teacher's request, and engage the teacher in social interaction. Behaviors coded as child behavior toward teacher that were not chosen as instances of child-initiated interactions were (a) re- 
sponses to teachers, such as complying with a teacher request, and (b) behaviors that disrupt class, such as calling out or pestering other children (NICHD ECCRN, 2002).

\subsubsection{Teacher-child relationship quality}

The NICHD SECCYD used the short form of the Student-Teacher Relationship Scale (STRS; Pianta, 2001) to assess teacher-child relationship quality in first grade. This 15-item version of the STRS is a teacher-report instrument measuring teachers' perceptions of their conflict and closeness with children. Items such as "Dealing with this child drains my energy" and "This child and I always seem to be struggling with each other" comprised the 8-item conflict subscale of the STRS: Short Form. Items such as "I share an affectionate, warm relationship with this child" and "It is easy to be in tune with what this child is feeling," comprised the 7-item closeness subscale. Teachers responded to items using a 5-point Likert-type rating scale where $1=$ definitely does NOT apply and 5 = definitely applies. Cronbach's alphas with the current sample were as follows: conflict $(a=.84)$ and closeness $(a=.64)$.

\section{Results}

\subsection{Descriptive analyses}

We conducted descriptive analyses of children's scores on temperament attributes and teacher-child relationship quality. On average, children showed moderate to high levels of attentional focusing and inhibitory control, and moderate levels of shyness. Teacher-child relationship quality was high for this sample, such that children's relationships with teachers were characterized by relatively low scores for conflict and high scores for closeness. In terms of teacher- and child-initiated interactions, although the average numbers of teacher- and child-initiated interactions were similar, the range of teacher-initiated interactions was much larger (0-50) than child-initiated interactions (0-23). Means and standard deviations are displayed in Table 1.

Correlational analyses revealed that all scores on all measures tended to have low correlations (i.e., less than .3), with the exception of inhibitory control and attentional focusing. These variables were somewhat highly related $(r=.53)$ and conceptually linked (Rothbart \& Bates, 1998), so they were averaged to form a composite variable called effortful control. Further examination of the correlation coefficients revealed small but significant correlations between the outcome variables (teacher-child conflict and closeness) and some of the child characteristics. Children lower in attentional focusing, inhibitory control, and shyness were rated as higher in conflict. They were also likely to receive more teacher-initiated interactions. Children with higher attentional focusing and inhibitory control were rated by their teachers as having close relationships and were more likely to initiate interactions with teachers. In addition, children perceived as high in conflict were perceived as low in closeness. Children rated lower in attentional focusing, inhibitory control, and shyness received more teacher-initiated interactions. Children with lower shyness ratings initiated more interactions with their teachers. Teacher-initiated interactions were positively related to childinitiated interactions $(r=.26)$. Table 1 shows the correlation matrix.

\subsection{Data analyses}

Path analyses, using structural equation models, were conducted to examine the direct effects of gender, shyness, and effortful control on teacher-child conflict and closeness, and the indirect effects of these child characteristics on teacher-child relationship quality through teacher-initiated interactions and child-initiated interactions. In our conceptual model, gender, shyness, and effortful control were proposed as exogenous, observed variables with links to teacher-initiated interactions, child-initiated interactions, and teacher-child conflict or closeness, all endogenous variables. In addition, we proposed bi-directional paths between teacher- and child-initiated interactions. Finally, our model proposes that teacher and child-initiated interactions influence conflict and closeness. To determine goodness of fit between the data and our models for conflict and closeness, we used the following fit indices: comparative fit index (CFI), Tucker-Lewis Index (TLI), non-linear index (NLI) (values close to 1 indicate good fit), and RMSEA (values less than .05 indicate good fit) (Fan, Thompson, \& Wang, 1999; Hu \& Bentler, 1999). The full proposed models are shown in Figures 1 (for conflict) and 2 (for closeness).

\subsubsection{Teacher-child conflict}

The path analysis model testing whether children's temperament and gender contributed directly and indirectly through teacher- and child-initiated interactions to teacher-child conflict appears in Figure 1 with standardized coefficients. Fit indices suggest good fit $(\mathrm{NFI}=.99, \mathrm{TLI}=.92, \mathrm{CFI}=.99, \mathrm{RMSEA}=.02)$. Results from the path analysis indicate that children's shyness $(\beta=-.107, p=.001)$, effortful control $(\beta=-.242, p<.001)$, and gender $(\beta=-.111, p=.001)$ all directly contributed to teacher-child conflict, such that children with lower shyness, lower effortful control, and boys were likely to have more conflict with teachers. In addition, less shyness predicted more child-initiated teacherchild interactions $(\beta=-.18, p=.001)$, and less effortful control predicted more teacher-initiated teacher-child interactions $(\beta=-.159, p<.001)$. More child-initiated interactions predicted more teacher-initiated interactions $(\beta=.883$, $p=.002)$, but more teacher-initiated interactions predicted fewer child-initiated interactions $(\beta=-.865, p=.01)$. However, neither the frequency of teacher-initiated nor the frequency of child-initiated interactions was found to contribute to teacher-child conflict. In sum, children's shyness, effortful control, and gender directly related to teacher-child 


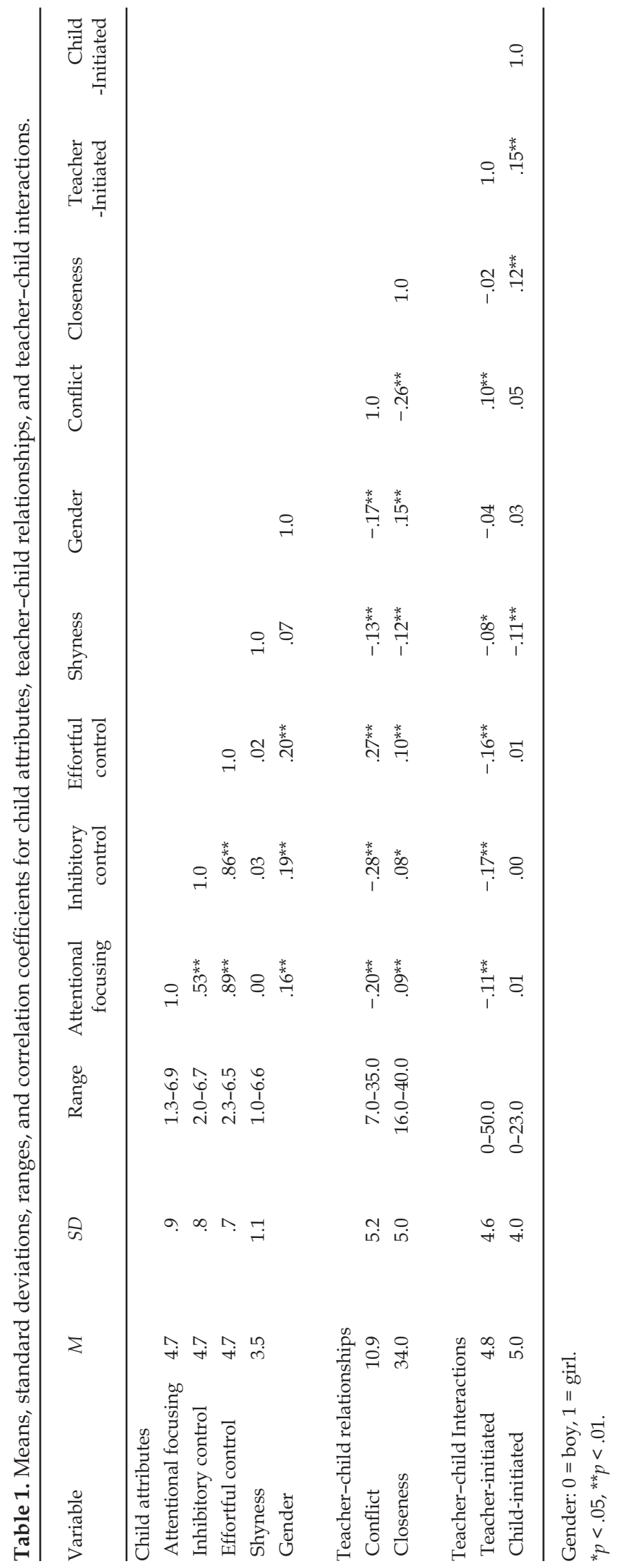




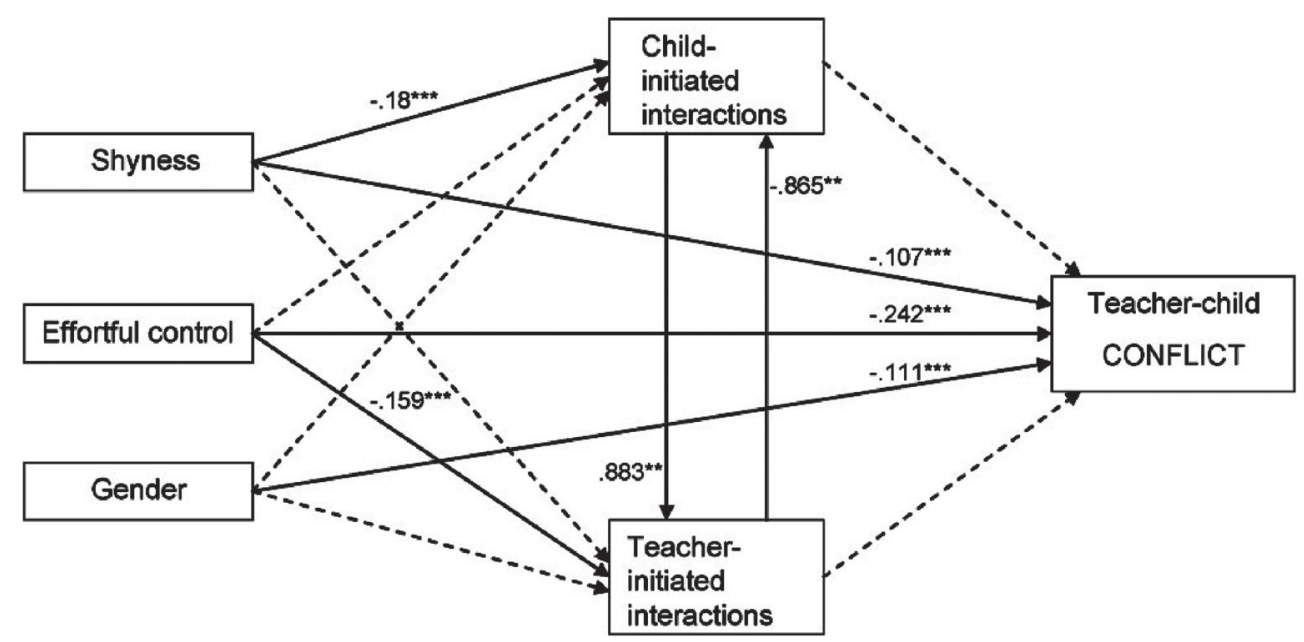

Figure 1. Path analysis model predicting teacher-child conflict with standardized coefficients.

conflict, shyness directly related to the frequency of child-initiated interactions, and effortful control directly related to the frequency of teacher-initiated interactions. However, shyness, effortful control, and gender did not contribute to teacher-child conflict indirectly through the frequency of teacher- or child-initiated interactions.

\subsubsection{Teacher-child closeness}

The path analysis model testing whether children's temperament and gender contributed directly and indirectly through teacher- and child-initiated interactions to teacher-child closeness appears in Figure 2 with standardized coefficients. The path analysis model indicated that children's temperament and gender contributed directly and indirectly to teacher-child closeness. The model fit indices indicated good fit (NFI $=.98$, TLI $=.91, \mathrm{CFI}=.99$, RMSEA =.02). As with conflict, children's shyness $(\beta=-.117, p<.001)$, effortful control $(\beta=.071, p=.042)$, and gender $(\beta=.137, p<.001)$ contributed to closeness such that children with lower shyness, higher effortful control, and girls were more likely to have close relationships with teachers. In addition, children's shyness was negatively related to the frequency of child-initiated interactions $(\beta=-.107, p=.001)$, and effortful control was negatively related to the frequency of teacher-initiated interactions $(\beta=-.159, p<.001)$. Shyer children were observed to initiate fewer interactions with teachers, and teachers were observed to initiate more interactions with children with lower effortful control. As with the model predicting teacher-child conflict, more child-initiated interactions predicted more teacherinitiated interactions $(\beta=.883, p=.002)$, but more teacher-initiated interactions predicted fewer child-initiated interactions $(\beta=-.865, p=.01)$. Finally, the frequency of child-initiated interactions was positively related to closeness $(\beta=.112, p=.001)$. These results suggest that children's shyness and effortful control contribute to closeness with teachers both directly and indirectly through the frequency of interactions with teachers. In sum, as with results predicting teacher-child conflict, shyness, effortful control, and gender directly related to teacher-child closeness, shyness directly contributed to the frequency of child-initiated interactions, and effortful control directly related to the frequency of teacher-initiated interactions. In addition, shyness was indirectly related to teacher-child closeness; children lower in shyness initiated more interactions with teachers, and more child-initiated interactions was related to more teacher-child closeness.

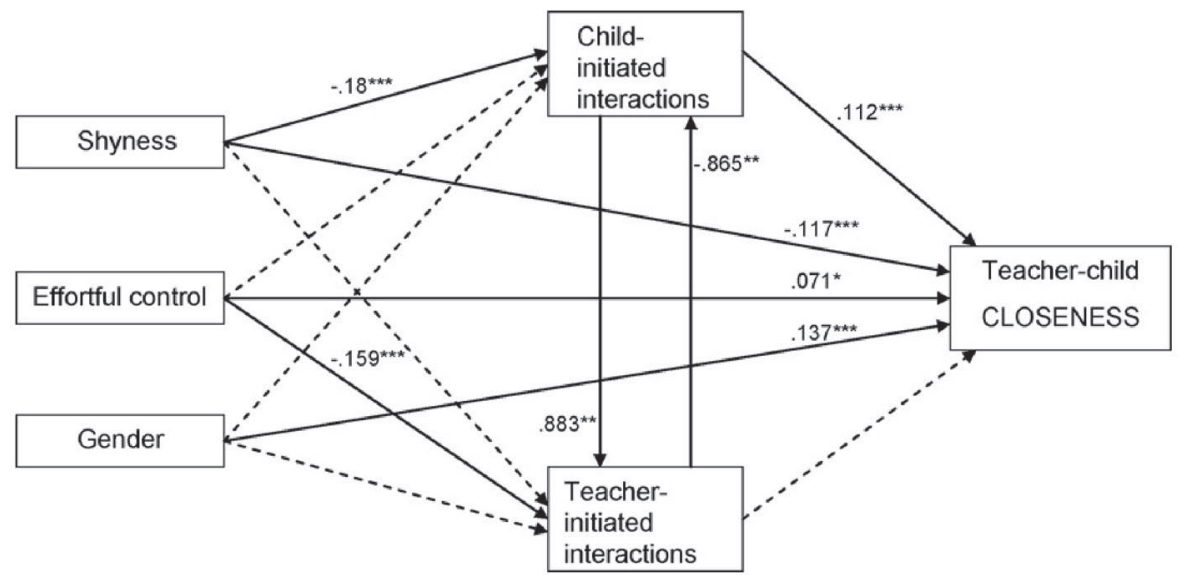

Figure 2. Path analysis model predicting teacher-child closeness with standardized coefficients. 


\section{Discussion}

Findings emerging from this study were primarily consistent with our hypotheses. As expected, children's shyness, effortful control, and gender predicted teachers' perceptions of the quality of their relationships with children. In terms of shyness, we found lower levels predicted more teacher-child conflict and more teacher-child closeness. For effortful control, children with lower levels were more likely to have conflict with teachers, and children with higher levels were more likely to have closeness with teachers. Congruent with previous research, our results showed that boys were more likely to have teacher-child relationships marked by conflict, and girls were more likely to have teacher-child relationships marked by closeness (Hamre \& Pianta, 2001; Saft \& Pianta, 2001; Silver et al., 2005). Children's shyness and effortful control also contributed to the frequency of teacher-child interactions; specifically, less shy children were likely to initiate more interactions with teachers, and children with lower levels of effortful control received more teacher-initiated interactions. We also found evidence supporting an indirect role for the frequency of teacher-child interactions in the relationship between children's shyness and teacher-child closeness. That is, shyer children initiated fewer interactions with teachers, and fewer child-initiated interactions with teachers predicted less teacher-child closeness. Finally, the frequency of child- and teacher-initiated interactions contributed to each other; more frequent child-initiated interactions contributed to more frequent teacher-initiated interactions, and more teacher-initiated interactions contributed to fewer child-initiated interactions. Taken together, these findings point to the important role of child characteristics in predicting the nature of children's relationships with teachers, having implications for further understanding of how children's attributes contribute to their development through bi-directional interactions with the environment (Teglasi, 1998).

\subsection{Shyness and teacher-child relationship quality}

Congruent with previous research (Rudasill et al., 2006; Rydell et al., 2005), our findings showed that children with lower levels of shyness were more likely to have relationships with teachers that were higher in conflict and closeness. In addition, our results lend support to the notion that the mechanism by which shyness relates to teacher-child closeness is, in part, the frequency of interactions between teachers and children.

In terms of teacher-child conflict, our finding that shyness was linked to levels of conflict is reflective of research indicating that uninhibited (i.e., not shy) children display higher levels of spontaneous speech and sociability than inhibited (i.e., shy) children (Asendorpf \& Meier, 1993; Caspi \& Silva, 1995; Rydell et al., 2005). Children who are not shy may be more likely to behave in ways that require teacher intervention, such as calling out or talking to classmates during instruction (Keogh, 2003). This type of behavior disrupts classroom activities and may be negatively perceived by teachers; indeed, Stuhlman and Pianta (2002) studied associations between teachers' perceptions of children's behavior and their ratings of teacher-child relationship quality and found that teachers are more likely to express negative feelings about relationships with children with whom they are observed to display negative behavior (i.e., angry, harsh, hostile).

Shyness also predicted teacher-child closeness, with shyer children less likely to have close relationships with teachers. This finding was consistent with our hypothesis; we predicted that shyer children would have less teacherchild closeness based on research suggesting that shyness poses risks to children's abilities to form positive relationships (Olson et al., 2005; Rothbart \& Bates, 1998; Rydell et al., 2005). Indeed, we also expected the frequency of teacher-child interactions to serve as a mechanism in this relationship because shyer children may be more hesitant to engage in social interactions and in the classroom this would translate to fewer interactions with teachers. Approaching the teacher involves uncertainty which is more likely to pose a problem for shyer children. Our findings bore this out; less shyness contributed to more child-initiated interactions, and more child-initiated interactions contributed to more closeness.

These findings can be interpreted in terms of the transactional nature of interactions between teachers and children. Research suggests shyer children tend to make fewer bids for attention from teachers (Coplan \& Prakash, 2003). So while less shy children are more likely to behave in ways that require teacher intervention, such as being off-task or acting out, for shyer children, this is rarely the case. Our research is congruent with other findings suggesting that shyer children receive less attention in classrooms (Finn et al., 1995; Keogh, 2003). However, there is evidence that teachers may be aware of the risk associated with children's withdrawn behavior and act in ways to buffer this risk. Coplan and Prakash (2003) found that, during free play, preschoolers rated as anxious or withdrawn received more teacher attention than children not rated as withdrawn. It could be that teachers seek opportunities for one-on-one interactions with shyer children because they have little contact with them in large group or whole class settings. Even so, findings from our study did not bear this out, perhaps because opportunities for one-on-one teacher-child interactions decrease precipitously as children move from preschool to elementary school where there is little opportunity for free play, and large group or whole class activities are common (Rimm-Kaufman \& Pianta, 2000). This puts the onus on children to initiate more interactions with teachers, and shyer children may be less likely to do so. Because close relationships depend on repeated teacher-child interactions, it follows that first grade teachers would be more likely to develop such relationships with children exhibiting lower levels of shyness.

Our results suggest that shyer children may be at risk for "invisibility" in the classroom. We found shyer children were less likely than others to develop conflictual or close relationships with teachers, and were also less likely to ini- 
tiate interactions with teachers, suggesting that shyer children were less connected to their teachers. This failure to "connect" may pose risks for children's success in school. For example, Ladd et al. (1999) found children's positive relationships with teachers predict greater class participation and achievement, and concluded that such relationships help children feel "... a sense of belonging or relatedness that empowers them to engage in, rather than withdraw from, classroom activities" (Ladd et al., 1999, p. 1386). Moreover, a study by Finn et al. (1995) revealed that inattentive-withdrawn children have lower academic achievement than all other students, including those classified as "disruptive." Thus, children who are less connected or even unnoticed in the classroom may be at-risk for feeling dissociated from school, and begin to "fall through the cracks" at a very early age.

\subsection{Effortful control}

Lower levels of effortful control predicted teacher-child conflict, and higher levels predicted teacher-child closeness, as expected. This is consistent with previous literature tying children's high effortful control to positive social outcomes, such as agreeableness (Cumberland-Li, Eisenberg, \& Reiser, 2004; Rothbart, Derryberry, et al., 1994), and follows from the conceptualization of effortful control as an internal regulatory system. That is, children vary in their ability to inhibit inappropriate behavior and activate appropriate behavior. For example, one child may be inclined to raise his hand to contribute to class, and another child may need constant reminders and behavioral cues to do so. The presence of this ability, in turn, contributes to the development of more positive relationships with teachers, which in turn, assist children in their efforts to meet the demands of the classroom (Blair, 2002). Indeed, children's abilities to regulate their behavior are key contributors to school "readiness," and under gird children's successful social and academic adjustment (Blair, 2002; Denham, 2006). It is easy to understand the implications of children's higher levels of effortful control in the classroom; children who can follow teacher directions, stand in line, and remain quiet are exhibiting effortful control and are, therefore, more able to meet typical classroom behavioral expectations. Indeed, this is congruent with our finding that children lower on effortful control experienced more teacher-initiated interactions. Thus, children with higher levels of effortful control were likely to be perceived more positively by teachers.

\subsection{Gender}

Findings from this study illustrate the importance of considering child gender in investigations of teacher-child relationship quality. The main effects for gender were consistent with previous literature (Hamre \& Pianta, 2001; Saft \& Pianta, 2001; Stuhlman \& Pianta, 2002) and our hypotheses. Specifically, boys were more likely to have conflictual relationships with teachers and girls were more likely to have close relationships with teachers. Indeed, these findings regarding gender and conflict are congruent with the extant literature showing that, as early as preschool, boys are more aggressive and show more externalizing behavior than girls (Dodge, Coie, \& Lynam, 2006; Kerr, Lopez, Olson, \& Sameroff, 2004). These findings also support previous research indicating that children's characteristics manifest themselves differently in boys' and girls' behavior. For example, Rimm-Kaufman and Kagan (2005) found that uninhibited boys talked more in class than uninhibited girls and inhibited boys and girls, and were the only children to increase their talking behavior (e.g., volunteering, yelling out) over time. The gender differences revealed herein provide further evidence for assertions that boys may be more at-risk for negative teacher-child relationships.

\subsection{Child- and teacher-initiated teacher-child interactions}

Our study's results provide evidence for a bi-directional or transactional relationship between child- and teacherinitiated teacher-child interactions. When child characteristics were included as predictor variables, more child-initiated interactions were associated with more teacher-initiated interactions, but more teacher-initiated interactions were associated with fewer child-initiated interactions. It is important to note that, in this study, child-initiated interactions had a positive valence (i.e., volunteering to help teacher, asking for assistance, engaging teacher in social conversation). However, the valence of teacher-initiated interactions could have been positive, negative, or neutral, as these were defined as one-on-one interactions between teacher and child for at least $5 \mathrm{~s}$.

This finding is best understood when considered within the contexts of the full models; that is, in our models, shyness was significantly and directly related to child-initiated interactions, and effortful control was significantly and directly related to teacher-initiated interactions. Let's first consider the relationship between child- and teacher-initiated interactions in the context of shyness. Here, lower levels of shyness predicted more frequent child-initiated interactions. More child-initiated interactions, in turn, predicted more frequent teacher-initiated interactions. As an example, consider an outgoing, approach-oriented (i.e., not shy) child in class. This child is likely to initiate many interactions with her teacher, eagerly volunteering to help and telling the teacher about exciting events in her life. Consequently, a teacher who recognizes a child's interest in interacting with the teacher is likely to reciprocate by initiating more interactions with the child, thus facilitating a close bond between child and teacher. This is not surprising, as other research has shown that shy children are less sociable than non-shy children (Asendorpf \& Meier, 1993; Caspi \& Silva, 1995; Rydell et al., 2005). Further this finding is consistent with the notion that children who are less shy are more effective at eliciting bids for their teachers' attention (Rimm-Kaufman \& Kagan, 2005). 
In terms of the relationship between child- and teacher-initiated interactions in the context of effortful control, lower levels of effortful control predicted more frequent teacher-initiated interactions. Remember that teacher-initiated interactions could be positive, negative, or neutral in nature, so it may be that our findings stem from the fact that children low in effortful control are likely to need more teacher attention to stay on-task in the classroom. Teachers would likely interact more frequently with children low on effortful control to provide reminders for behavior and attention, and these interactions may be negatively viewed by children as restrictive in nature. Consequently, more teacher-initiated interactions would contribute to fewer child-initiated interactions, especially in light of the fact that child-initiated interactions in our study had positive valences. It could also be that children receiving more teacherinitiated interactions were content with their level of teacher attention and did not feel compelled to seek more attention by initiating interactions with teachers. It is important to put this in context of some of the issues children resolve in early childhood classrooms. Specifically, children make the transition from depending on adults to assist in their regulation to developing their own self-regulation strategies (Bronson, 2000).

\subsection{Limitations}

Three limitations require mention. First, data for this study were not collected concurrently. Temperament assessments were conducted two years prior to first grade assessments. Although children's temperament characteristics are fairly stable (Kagan et al., 1988; Resnick et al., 1986; Rimm-Kaufman \& Kagan, 2005), these assessments occurred prior to a major developmental shift accompanying the transition to school (Sameroff \& Haith, 1996). However, this may also be viewed as a strength of the study because children's temperament assessments were conducted in early childhood, rather than later when an individuals' feelings and actions are viewed as personality traits (Kagan \& Fox, 2006). Second, ratings of temperament and teacher-child relationship quality would have been strengthened through the use of multiple raters and observations. Third, because this study's design is correlational, no conclusions about causation can be drawn from our findings.

\subsection{Future research and implications}

According to Sameroff's (1983) Transactional Model and Rimm-Kaufman and Pianta's (2000) Ecological and Dynamic Model of Transition, children's relationships are multi-determined and result from the interplay between characteristics of children and teachers. From this perspective, the findings from this study suggest several areas for future research. First, because these results elucidate the contributions of shyness and effortful control to the nature of teacher-child relationships, it is important to extend this research to include examinations of the role of classroom and school context in the relation between child characteristics and teacher-child relationship quality. We know that certain attributes of classroom quality, such as emotional support and instructional support, promote children's positive outcomes in school, but we know less about for whom these attributes of classroom quality matter most (Brock, Nishida, Chiong, Grimm, \& Rimm-Kaufman, 2007; Hamre \& Pianta, 2005; Mashburn et al., 2008; O'Connor \& McCartney, 2007; Stipek, Feiler, Daniels, \& Milburn, 1995). For example, a highly emotionally supportive classroom may matter more for children low in effortful control compared to those higher in effortful control. Such extensions of this research can contribute to a better understanding of the intricacies of teacher-child relationship formation.

Second, given the findings that shyer children are more at-risk for poor teacher-child relationships, this research could be extended with an investigation of how children's shyness moderates the success of interventions designed to increase bonding to school. Children's school bonding may depend, in part, on their willingness to interact socially with peers and teachers. Third, this study employed a variable-centered approach, thus requiring assumptions about homogeneity among children in how shyness, effortful control, and gender related to teacher-child relationship quality (Laursen \& Hoff, 2006). This research could be extended through investigation using a person-centered approach which would allow for a deeper understanding of the differences among children with regard to the contributions of shyness, effortful control, and gender to the quality of relationships with teachers.

Educational practice may also be informed by the findings reported here. This study represents another step toward understanding elements of young children's risk in the classroom. Our results point to potential, significant predictors of the quality of an important early relationship. As such, we assert that this study can inform teacher training and practice in three ways. First, teacher trainers can use these findings to broaden preservice teachers' conceptualizations of children with whom they may not be able to easily develop positive relationships. Our findings point to children's shyness as a risk factor for young children's abilities to feel connected to their teachers. New and preservice teachers may be particularly focused on behavior management strategies as they enter the profession, paying less attention to children who are unlikely to cause disruptions in class, but are more likely to go unnoticed in the classroom. Studies such as this one can help teacher trainers illustrate the more subtle risks associated with shyness. It is critical that teachers are aware not only of children with whom they may have a difficult relationship, but also those who they may fail to notice and, thus, may not form meaningful relationships.

Second, our study's results speak directly to teacher behavior in the classroom. Specifically, children who initiated more interactions with their teachers were more likely to have close relationships with their teachers, offering support for more child-centered activities in classrooms. Teachers and teacher trainers should focus on classroom activities that promote child-initiated interactions, and de-emphasize teacher-directed, large group activities. Shy children, in particular, will be more likely to initiate interactions with teachers and other children in small group and one-on-one contexts than in large group settings (Keogh, 2003). 
Third, these findings may help teachers identify children for whom teacher-child and other key relationships (such as peer relationships) may be difficult. With early identification, teachers can team with other school personnel and parents to develop a plan for building social interaction skills in order to promote positive relationships for children who are less likely to initiate interactions with teachers and others.

Acknowledgments - The work reported herein was supported in part by the National Institute of Child Health and Human Development (NICHD) Study of Early Child Care (U10-HD25449), NICHD R21-43750, and by the University of Virginia Interdisciplinary Doctoral Training Program in Education Sciences, Institute of Education Sciences U.S. Department of Education Award \#R305B040049.

\section{References}

Asendorpf and Meier, 1993 - J. B. Asendorpf and G. H. Meier, Personality effects on children's speech in everyday life: Sociability-mediated exposure and shyness-mediated reactivity to social situations, Journal of Personality and Social Psychology 64 (1993), pp. 1072-1083.

Baker, 2006 - J. A. Baker, Contributions of teacher-child relationships to positive school adjustment during elementary school, Journal of School Psychology 44 (2006), pp. 211-229.

Birch and Ladd, 1997 - S. H. Birch and G. W. Ladd, The teacher-child relationship and children's early school adjustment, Journal of School Psychology 35 (1997), pp. 61-79.

Blair, 2002 - C. Blair, School readiness: Integrating cognition and emotion in a neurobiological conceptualization of children's functioning at school entry, American Psychologist 57 (2002), pp. 111-127.

Blair et al., 2004 - K. A. Blair, S. A. Denham, A. Kochanoff, and B. Whipple, Playing it cool: Temperament, emotion regulation, and social behavior in preschoolers, Journal of School Psychology 42 (2004), pp. 419-443.

Brock et al., 2007 - L. L. Brock, T. K. Nishida, C. Chiong, K. J. Grimm, and S. E. Rimm-Kaufman, Children's perceptions of the classroom environment and social and academic performance: A longitudinal analysis of the contribution of the responsive classroom approach, Journal of School Psychology 46 (2007), pp. 129-149.

Bronson, 2000 - M. B. Bronson, Self-regulation in early childhood: Nature and nurture, Guilford Press, New York (2000)

Buss et al., 1993 - K. Buss, J. Gingles, and J. Price, Parent-teacher temperament ratings and student success in reading, Reading Psychology: An International Quarterly 14 (1993), pp. 311-323.

Caspi and Silva, 1995 - A. Caspi and P. A. Silva, Temperament qualities at age three predict personality traits in young adulthood: Longitudinal evidence from a birth cohort, Child Development 66 (1995), pp. 486-498.

Coplan and Prakash, 2003 - R. J. Coplan and K. Prakash, Spending time with teacher: Characteristics of preschoolers who frequently elicit versus initiate interactions with teachers, Early Childhood Research Quarterly 18 (2003), pp. 143-158.

Coplan et al., 2004 - R. J. Coplan, K. Prakash, K. O'Neil, and M. Armer, Do you "want" to play? Distinguishing between conflicted-shyness and social disinterest in early childhood, Developmental Psychology 40 (2004), pp. 244-258.

Cumberland-Li et al., 2004 - A. Cumberland-Li, N. Eisenberg, and M. Reiser, Relations of young children's agreeableness and resiliency to effortful control and impulsivity, Social Development 13 (2004), pp. 193-212.

Denham, 2006 - S. A. Denham, Social-emotional competence as support for school readiness: What is it and how do we assess it?, Early Education and Development 17 (2006), pp. 57-89.

DeSchipper et al., 2004 - J. C. DeSchipper, L. W. C. Tavecchio, M. H. Van Ijzendoorn, and J. Van Zeijl, Goodness-of-fit in center day care: Relations of temperament, stability, and quality of care with the child's adjustment, Early Childhood Research Quarterly 19 (2004), pp. $257-272$.

Dodge et al., 2006 - K. A. Dodge, J. D. Coie, and D. Lynam, Aggression and antisocial behavior in youth (6th ed.). In: N. Eisenberg, Editor, Social, emotional, and personality development Vol. 3, John Wiley \& Sons, Inc., New York (2006), pp. 719-788.

Eisenhower et al., 2007 A. S. Eisenhower, B. L. Baker, and J. Blacher, Early student-teacher relationships of children with and without intellectual disability: Contributions of behavioral, social, and self-regulatory competence, Journal of School Psychology 45 (2007), pp. 363-383.

Evans, 1992 - M. A. Evans, Control and paradox in teacher conversations with shy children, Canadian Journal of Behavioural Science 24 (1992), pp. 502-516.

Evans, 1996 - M. A. Evans, Reticent primary grade children and their more talkative peers: Verbal, nonverbal, and self-concept characteristics, Journal of Educational Psychology 88 (1996), pp. 739-749.

Fantuzzo et al., 2004 - J. Fantuzzo, C. McWayne, M. A. Perry, and S. Childs, Multiple dimensions of family involvement and their relations to behavioral and learning competencies for urban, low-income children, School Psychology Review 33 (2004), pp. 467-480.

Fan et al., 1999 - X. Fan, B. Thompson, and L. Wang, The effects of sample size, estimation methods, and model specification on SEM fit indices, Structural Equation Modeling: A Multidisciplinary Journal 6 (1999), pp. 56-83.

Finn et al., 1995 - J. D. Finn, G. M. Pannozzo, and K. E. Voelkl, Disruptive and inattentive-withdrawn behavior and achievement among fourth graders, The Elementary School Journal 95 (1995), pp. 421-434.

Goldsmith et al., 2001 - H. H. Goldsmith, N. Aksan, M. Essex, N. A. Smider, and D. L. Vandell, Temperament and socioemotional adjustment to kindergarten: A multi-informant perspective. In: T. D. Wachs and G. A. Kohnstamm, Editors, Temperament in context, Erlbaum, Mahwah, NJ (2001), pp. 103-138.

Hamre and Pianta, 2001 - B. K. Hamre and R. C. Pianta, Early teacher-child relationships and the trajectory of children's school outcomes through eighth grade, Child Development 72 (2001), pp. 625-638.

Hamre and Pianta, 2005 - B. K. Hamre and R. C. Pianta, Can instructional and emotional support in the first-grade classroom make a difference for children at risk of school failure?, Child Development 64 (2005), pp. 949-967.

Henderson and Fox, $1998 \cdot$ H. A. Henderson and N. A. Fox, Inhibited and uninhibited children: Challenges in school settings, The School Psychology Review 27 (1998), pp. 492-505.

Hu and Bentler, 1999 - L. Hu and P. M. Bentler, Cutoff criteria for fit indexes in covariance structure analysis: Conventional criteria versus new alternatives, Structural Equation Modeling 6 (1999), pp. 1-55.

Kagan, 1994 • J. Kagan, Galen's prophecy: Temperament in human nature, HarperCollins Publishers, New York (1994).

Kagan and Fox, 2006 - J. Kagan and N. Fox, Biology, culture, and temperamental issues (6th ed.). In: W. Damon and N. Eisenberg, Editors, Handbook of child psychology: Social, emotional, and personality development, Vol. 3, John Wiley \& Sons, Inc, New York (2006), pp. 167-225.

Kagan et al., 1988 - J. Kagan, J. S. Resnick, N. Snidman, J. Gibbons, and M. O. Johnson, Childhood derivatives of inhibition and lack of inhibition to the unfamiliar, Child Development 59 (1988), pp. 1580-1589.

Kagan et al., 1992 • J. Kagan, N. Snidman, and D. Arcus, Initial reactions to unfamiliarity, Current Directions in Psychological Science 1 (1992), pp. 171-174.

Kagan et al., 1998 - J. Kagan, N. Snidman, and D. Arcus, Childhood derivatives of high and low reactivity in infancy, Child Development 69 (1998), pp. $1483-1493$.

Keogh, 2003 - B. Keogh, Temperament in the classroom: Understanding individual differences, Paul H. Brookes, Baltimore, MD (2003).

Kerr et al., 2004 - D. C. R. Kerr, N. L. Lopez, S. L. Olson, and A. J. Sameroff, Parental discipline and externalizing behavior problems in early childhood: The roles of moral regulation and child gender, Journal of Abnormal Child Psychology 32 (2004), pp. 369-383.

Kesner, 2000 - J. E. Kesner, Teacher characteristics and the quality of teacher-child relationships, Journal of School Psychology 38 (2000), pp. 133-149.

Kochanska, 1991 - G. Kochanska, Patterns of inhibition to the unfamiliar in children of normal and affectively ill mothers, Child Development 62 (1991), pp. 250-263. 
Ladd et al., 1999 • G. W. Ladd, S. H. Birch, and E. S. Buhs, Children's social and scholastic lives in kindergarten: Related spheres of influence?, Child Development 70 (1999), pp. 1373-1400.

Ladd and Burgess, 1999 • G. W. Ladd and S. R. Burgess, Charting the relationship trajectories of aggressive, withdrawn, and aggressive/withdrawn children during early grade school, Child Development 70 (1999), pp. 910-929.

La Paro et al., 2004 • K. M. La Paro, R. C. Pianta, and M. Stuhlman, The Classroom Assessment Scoring System: Findings from the prekindergarten year, The Elementary School Journal 104 (2004), pp. 409-426.

Laursen and Hoff, 2006 - B. Laursen and E. Hoff, Person-centered and variable-centered approaches to longitudinal data, Merrill-Palmer Quarterly 52 (2006), pp. 377-389.

Lerner et al., 1985 - J. V. Lerner, R. M. Lerner, and S. Zabski, Temperament and elementary school children's academic performance: A test of 'goodness-of-fit' model, Journal of Child Psychology 26 (1985), pp. 125-136.

Mantzicopoulos, 2005 - P. Mantzicopoulos, Conflictual relationships between kindergarten children and their teachers: Associations with child and classroom context variables, Journal of School Psychology 43 (2005), pp. 425-442.

Mashburn et al., 2008 • A. J. Mashburn, R. C. Pianta, B. K. Hamre, J. T. Downer, O. A. Barbarin, and D. Bryant et al., Measures of classroom quality in prekindergarten and children's development of academic, language, and social skills, Child Development 79 (2008), pp. $732-749$.

NICHD ECCRN, 1993 - National Institute of Child Health and Human Development, Early Child Care Research Network. (1993). The NICHD study of early child care: A comprehensive longitudinal study of young children's lives. ERIC Document Reproduction Service, No. ED 3530870.

NICHD ECCRN, 2002 - National Institute of Child Health and Human Development, Early Child Care Research Network, The relation of global firstgrade classroom environment to structural classroom features and teacher and student behavior, Elementary School Journal 102 (2002), pp. 367-387.

Nelson et al., 2005 - L. J. Nelson, K. H. Rubin, and N. A. Fox, Social withdrawal, observed peer acceptance, and the development of self-perceptions in children ages 4 to 7 years, Early Childhood Research Quarterly 20 (2005), pp. 185-200.

$\mathrm{O}^{\prime}$ Connor and McCartney, 2007 - E. O'Connor and K. McCartney, Examining teacher-child relationships and achievement as part of an ecological model of development, American Educational Research Journal 44 (2007), pp. 240-269.

Olson et al., 2005 - S. L. Olson, A. J. Sameroff, D. C. R. Kerr, N. L. Lopez, and H. M. Wellman, Developmental foundations of externalizing problems in young children: The role of effortful control, Development and Psychopathology 17 (2005), pp. 25-45.

Pianta, 1999 - R. C. Pianta, Enhancing relationships between children and teachers, American Psychological Association, Washington, DC (1999).

Pianta, 2001 - R. C. Pianta, Student-Teacher Relationship Scale, Psychological Assessment Resources, Inc., Odessa, FL (2001).

Pianta et al., 1997 - R. C. Pianta, S. L. Nimetz, and E. Bennett, Mother-child relationships, teacher-child relationships, and school outcomes in preschool and kindergarten, Early Childhood Research Quarterly 12 (1997), pp. 263-280.

Pianta et al., 1995 - R. C. Pianta, M. S. Steinberg, and K. B. Rollins, The first two years of school: teacher-child relationships and deflections in children's classroom adjustment, Development and Psychopathology 7 (1995), pp. 295-312.

Posner and Rothbart, 2000 • M. I. Posner and M. K. Rothbart, Developing mechanisms of self-regulation, Development and Psychopathology 12 (2000), pp. 427-441.

Resnick et al., 1986 • J. S. Resnick, J. Kagan, N. Snidman, M. Gersten, K. Baak, and A. Rosenberg, Inhibited and uninhibited children: A follow-up study, Child Development 57 (1986), pp. 660-680.

Rimm-Kaufman and Kagan, 2005 - S. E. Rimm-Kaufman and J. Kagan, Infant predictors of kindergarten behavior: The contribution of inhibited and uninhibited temperament types, Behavioral Disorders 30 (2005), pp. 329-345.

Rimm-Kaufman and Pianta, 2000 - S. E. Rimm-Kaufman and R. C. Pianta, An ecological perspective on the transition to kindergarten: A theoretical framework to guide empirical research, Journal of Applied Developmental Psychology 21 (2000), pp. 491-511.

Rothbart et al., 1994a - M. K. Rothbart, S. A. Ahadi, and K. L. Hershey, Temperament and social behavior in childhood, Merrill-Palmer Quarterly 40 (1994), pp. 21-39.

Rothbart et al., 2001 - M. K. Rothbart, S. A. Ahadi, K. L. Hershey, and P. Fisher, Investigations of temperament at 3 to 7 years: The children's behavioral questionnaire, Child Development 72 (2001), pp. 1394-1408.

Rothbart and Bates, 1998 - M. K. Rothbart and J. E. Bates, Temperament (5th ed.). In: W. Damon and N. Eisenberg, Editors, Handbook of child psychology: Social, emotional, and personality development, vol. 3, John Wiley \& Sons, Inc., New York (1998), pp. 105-176.

Rothbart and Bates, 2006 - M. K. Rothbart and J. E. Bates, Temperament (6th ed.). In: W. Damon and N. Eisenberg, Editors, Handbook of child psychology: Social, emotional, and personality development, vol. 3, John Wiley \& Sons, Inc., New York (2006), pp. 99-166.

Rothbart et al., 1994b - M. K. Rothbart, D. Derryberry, and M. I. Posner, A psychobiological approach to the development of temperament. In: J. E. Bates and T. D. Wachs, Editors, Temperament: Individual differences at the interface of biology and behavior, American Psychological Association, Washington, DC (1994), pp. 83-116.

Rothbart et al., 2006 - M. K. Rothbart, M. I. Posner, and J. Kieras, Temperament, attention, and the development of self-regulation. In: K. McCartney and D. Phillips, Editors, Blackwell handbook of early child development, Blackwell, Malden, MA (2006), pp. 338-357.

Rubin et al., 1998 - K. H. Rubin, W. Bukowski, and J. G. Parker, Peer interactions, relationships, and groups (5th ed.). In: N. Eisenberg, Editor, Social, emotional, and personality development Vol. 3, John Wiley \& Sons, Inc., New York (1998), pp. 619-700.

Rudasill et al., 2006 - K. M. Rudasill, S. E. Rimm-Kaufman, L. M. Justice, and K. Pence, Temperament and language skills as predictors of teacher-child relationships in preschool, Early Education and Development 17 (2006), pp. 271-291.

Rydell et al., 2005 - A. Rydell, G. Bohlin, and L. B. Thorell, Representations of attachment to parents and shyness as predictors of children's relationships with teachers and peer competence in preschool, Attachment and Human Development 7 (2005), pp. 187-204.

Saft and Pianta, 2001 - E. W. Saft and R. C. Pianta, Teachers' perceptions of their relationships with students: Effects of child age, gender, and ethnicity of teachers and children, School Psychology Quarterly 16 (2001), pp. 125-141.

Sameroff, 1983 - A. J. Sameroff, Developmental systems: Contexts and evolution (4th ed.). In: P. H. Mussen, Editor, History, theory, and methods Vol. 1, John Wiley \& Sons, Inc., New York (1983), pp. 237-294.

Sameroff and Fiese, 2000 - A. J. Sameroff and B. H. Fiese, Models of development and developmental risk. In: C. H. Zeanah Jr., Editor, Handbook of infant mental health (2nd ed.), Guilford, New York (2000), pp. 3-19.

Sameroff and Haith, 1996 - A. J. Sameroff and M. M. Haith, The five to seven year shift: The age of reason and responsibility, University of Chicago Press, Chicago, IL (1996)

Sameroff and MacKenzie, 2003 - A. J. Sameroff and M. J. MacKenzie, Research strategies for capturing transactional models of development: The limits of the possible, Development and Psychopathology 15 (2003), pp. 613-640.

Silver et al., 2005 - R. B. Silver, J. R. Measelle, J. M. Armstrong, and M. J. Essex, Trajectories of classroom externalizing behavior: Contributions of child characteristics, family characteristics, and the teacher-child relationship during the school transition, Journal of School Psychology 43 (2005), pp. $39-60$.

Stipek et al., 1995 - D. Stipek, R. Feiler, D. Daniels, and S. Milburn, Effects of different instructional approaches on young children's achievement and motivation, Child Development 66 (1995), pp. 209-223.

Strelau, 1983 - J. Strelau, Temperament-personality-activity, Academic Press, New York (1983).

Stuhlman and Pianta, 2002 - M. W. Stuhlman and R. C. Pianta, Teachers' narratives about their relationships with children: Associations with behavior in classrooms, School Psychology Review 31 (2002), pp. 148-163.

Teglasi, 1998 - H. Teglasi, Temperament constructs and measures, School Psychology Review 27 (1998), pp. 564-585.

Thomas and Chess, 1977 - A. Thomas and S. Chess, Temperament and development, Brunner/Mazel, Oxford, England (1977).

Valiente et al., 2008 - C. Valiente, K. Lemery-Chalfant, J. Swanson, and M. Reiser, Prediction of children's academic competence from their effortful control, relationships, and classroom participation, Journal of Educational Psychology 100 (2008), pp. 67-77.

Zhou et al., 2007 - Q. Zhou, C. Hofer, N. Eisenberg, M. Reiser, T. L. Spinrad, and R. A. Fabes, The developmental trajectories of attentional focusing, attentional and behavioral persistence, and externalizing problems during school-age years, Developmental Psychology 43 (2007), pp. $369-385$. 